\title{
Bonding Analysis in [1.1.1]Propellane and [1.1.1]Bicyclopentane using Orbital Forces. The Myth of the "Inverted Bond"
}

\author{
Rubén Laplaza, ${ }^{[\mathrm{b}]}$ Julia Contreras-Garcia ${ }^{[\mathrm{cc}}$, Franck Fuster ${ }^{\text {, }}{ }^{[\mathrm{c}]}$, François Volatron ${ }^{[\mathrm{c}]}$, and Patrick \\ Chaquin*[a]
}

\begin{abstract}
The properties of the "inverted bond" in [1.1.1]propellane 1 are investigated by two methods. Firstly we study $\mathrm{H}_{3} \mathrm{C}-\mathrm{C}$ models of $\mathrm{C}-\mathrm{C}$ bonds with frozen $\mathrm{HCC}$ angles reproducing the constraints of various degrees of "inversion". Secondly, the molecular orbital (MO) properties of [1.1.1]propellane $\mathbf{1}$ and [1.1.1]bicyclopentane 2 are analyzed with the help of orbital forces as a criterion of bonding/antibonding character and as a basis to evaluate in-situ bond energies. Triplet state of $\mathbf{1}$ and cationic species of $\mathbf{1}$ and $\mathbf{2}$ are also considered to comfort the bonding/antibonding character of MOs in the parent molecules. Both approaches shows an essentially nonbonding or slightly repulsive character of the $\sigma$ central CC interaction in propellane: the so-called 'inverted' bond, as resulting from a $\sigma$ overlap of the two s-p hybrids by their smaller lobes, appears devoid of physical basis. The bonding of central CC in $\mathbf{1}$ is thus only due to $\pi$-type MOs (also called 'banana' MOs or 'bridge' MOs) and its total energy is evaluated to ca. $60 \mathrm{kcal} / \mathrm{mol}$. In bicyclopentane 2, despite a strong $\sigma$-type repulsion, a weak bonding $(20 \mathrm{kcal} / \mathrm{mol})$ exists between both central $\mathrm{CC}$, also due to $\pi$-type interactions, though no formal bond is present.
\end{abstract}

\section{Introduction}

The nature of the central CC bonding in [1.1.1.] propellane 1 has been the subject of a number of studies, converging towards the possibility of a relatively strong C-C sigma "inverted bond". This bond would result from the overlap of the two s-p hybrids by their smaller lobe.

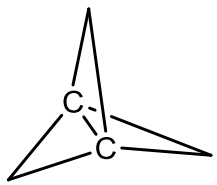

1

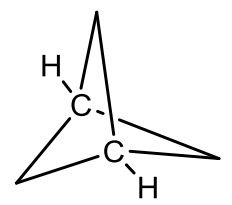

2

[a] Pr. P. Chaquin

Laboratoire de Chimie Théorique (LCT)

Sorbonne Université, CNRS, F-75005 Paris

E-mail : chaquin@lct.jussieu.fr

[b] R. Laplaza

Laboratoire de Chimie Théorique (LCT)

Sorbonne Université, CNRS, F-75005 Paris

Departamento de Química Física

Universidad de Zaragoza

50009 Zaragoza, Spain

[c] Dr. J. Contreras-Garcia, Dr. F. Fuster, Dr. F. Volatron

Laboratoire de Chimie Théorique (LCT)

Sorbonne Université, CNRS, F-75005 Paris 
On the one hand, based on the thermodynamics of the transformation $\mathbf{2} \rightarrow \mathbf{1}+2 \mathrm{H}(\Delta \mathrm{E} \approx 140$ $\mathrm{kcal} / \mathrm{mol}$ ), a bond energy of ca. $60 \mathrm{kcal}^{\mathrm{mol}}{ }^{-1}$ was deduced for the central C-C bond of $1 .{ }^{1,2,3}$ Localized MOs and bond indices also point at a significant interaction between the carbons of propellane. ${ }^{4}$ From VB calculations, in situ bonding energy of this same bond was found to be ca. $77 \mathrm{kcal}^{\mathrm{mol}} \mathrm{m}^{-1}$, only $19.4 \mathrm{kcal}^{\mathrm{mol}}{ }^{-1}$ less than that of the $\mathrm{C}-\mathrm{C}$ bond of ethane, due to the presence of a "charge-shift" bonding. ${ }^{5}$ On the other hand, this inverted bond involves a weak or even negative population overlap, and the total electron density in the bonding region was found similar for $\mathbf{1}$ and 2. ${ }^{6}$ The HOMO of 1, associated with the $\sigma \mathrm{C}-\mathrm{C}$, bond has been found to be antibonding on the basis of the $\mathrm{MO}$ energy variation as a function of the $\mathrm{CC}$ distance. ${ }^{7}$ Moreover, an essentially non-bonding character of this HOMO was deduced from photoelectron spectrum, ${ }^{8}$ while electron attachment revealed a low energy $\sigma^{*}$ LUMO, which also points at a weak bonding. ${ }^{9} A$ bond path was found, with a critical point, from X-ray study, but with no appreciable charge accumulation at this point. ${ }^{10}$ It was thus suggested that the low energy difference between $\mathbf{1}+2 \mathrm{H}$ and $\mathbf{2}$ could result from a strong fourelectron repulsion between both $\mathrm{C}-\mathrm{H}$ in $\mathbf{2}$ rather than from a strong $\mathrm{CC}$ bonding in $\mathbf{1},{ }^{2}$ and thus that CC bonding in 1 should be ensured by 2-electron 3-centre interactions (or "banana bonds") arising from MOs located on the "wings" of propellane.

In this work, we first study 'in silico' models of inverted bonds at various degrees of inversion. Then, we will perform analyses of propellane $\mathbf{1}$, bicyclopentane $\mathbf{2}$ and some of their cationic and excited states by means of Dynamic Orbital Forces $(D O F)^{11}$ as a measure of the bonding/antibonding character of Molecular Orbitals (MO). This quantity is the MO energy derivative with respect to a given geometrical parameter, generally a bond length. In this case, it is equal to the force exerted on the nuclei along this bond by removal of one electron from a given $\mathrm{MO}$, in the frozen $\mathrm{MO}$ approximation. As a matter of fact, according to Koopman's theorem, the energy $\varepsilon_{i}$ of the $i^{\text {th }} \mathrm{MO}$ is:

$$
\varepsilon_{i}=E^{0}-E_{i}^{+}
$$

where $E^{0}$ is the Hartree-Fock $(\mathrm{H}-\mathrm{F})$ energy of neutral molecule, and $E_{i}^{+}$is the energy of the cation resulting from the removal of one electron from the $i^{\text {th }} \mathrm{MO}$. The derivative with respect to an internuclear distance $R$ yields:

$$
\frac{d \varepsilon_{i}}{d R}=\frac{d E^{0}}{d R}-\frac{d E_{i}^{+}}{d R}
$$

If the geometry has been taken at its equilibrium value $R_{e}$ in the neutral species, $\mathrm{d} E^{0} / \mathrm{d} R=0$ and:

$$
\left(\frac{d \varepsilon_{i}}{d R}\right)_{R=R_{e}}=-\left(\frac{d E_{i}^{+}}{d R}\right)_{R=R_{e}}
$$

The DOFs must be distinguished from Bader's "static" forces ${ }^{12}$ and has been successfully used to evaluate the local MO bonding/antibonding character: a positive DOF value corresponds to a bonding $\mathrm{MO}^{13}$ and vice versa. Moreover, it has been shown that this value is related in a semi-quantitative way to changes in some physical quantities upon ionization or protonation ${ }^{14}$ and is a useful tool in the study of reaction mechanisms. ${ }^{15}$

On the basis of DOFs, we will propose reasonable values of in-situ bond energies of CC bonds in $\mathbf{1}$ and in 2. 


\section{Computational details}

The $\mathrm{C}_{2} \mathrm{H}_{6}$ models of inverted bonds and their $\mathrm{C}-\mathrm{C}$ binding energies were computed at the $\operatorname{CCSD}(\mathrm{T}) / \mathrm{CC}-$ pVQZ level. All other systems were optimized at the MP2/cc-pVTZ level. The DOFs were computed by a small finite bond length difference (typically 2-8 $10^{-3} \AA$ ); they are given in atomic units (hartree/bohr), at the H-F cc-pVTZ level. For open shell species, ROHF MOs were considered. The GAUSSIAN 09 series of programs ${ }^{16}$ was used throughout this work.

\section{Results and discussion}

\section{1. 'In silico' models of "inverted" and "semi-inverted" bonding}

The main problem to conclude to the strength of the inverted bond in propellane is the evident impossibility to break this bond, in order to compute its dissociation energy, without destruction of the whole molecule. To avoid this problem, we have studied staggered $\mathrm{C}_{2} \mathrm{H}_{6}$ models in which the six HCC angles have been frozen from $120^{\circ}$ down to $70^{\circ}$, including their value in ethane $\left(111.2^{\circ}\right)$ the other parameters, namely $\mathrm{CH}$ and $\mathrm{CC}$ distances being optimized. Dissociation energies De were calculated with respect to both isolated $\mathrm{CH}_{3}$ moieties with the same geometry and in their optimal planar geometry.

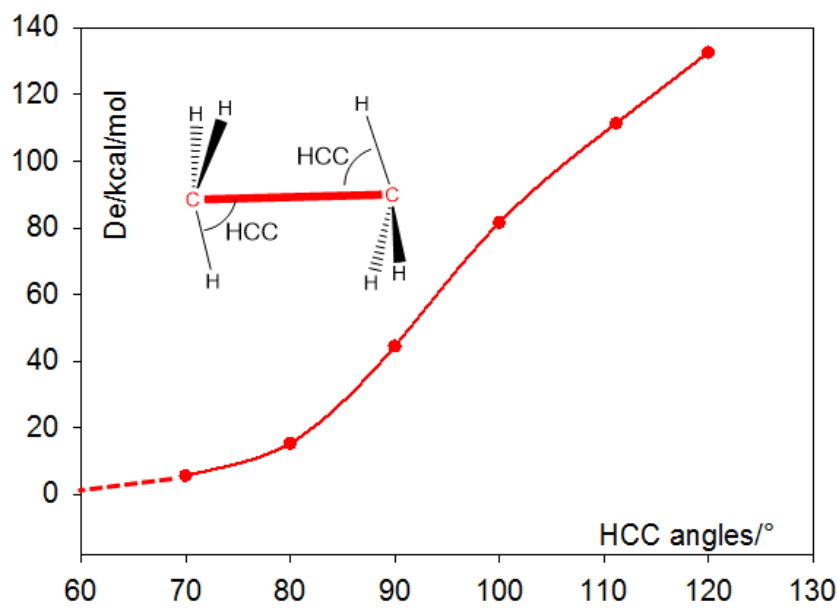

Figure 1. C-C bond dissociation energy De as a function of the HCC angles (CCSD(T)/cc-pVQZ), with respect to $\mathrm{CH}_{3}$ units within the same geometry. Extrapolation to $60^{\circ}$ was added with a broken line.

Results are reported in Fig. 1 and Table 1. We observe that De decreases rapidly as the HCC angle closes and is nearly vanishing for $\mathrm{HCC}=70^{\circ}$. It should be noted that since neither the BSSE nor the zero point correction were taken into account, these values are presumably even overestimated. No minimum was found for $\mathrm{HCC}=60^{\circ}$ (approximate value of the corresponding angle in 1 ), thus suggesting a dissociation energy close to zero, as also supported by extrapolation of the curve in Fig. 1. It can be noted that with the angle of $120^{\circ}$, greater than in an optimized ethane, the dissociation energy increases. This result agrees with the short CC bond ( $1.436 \AA$ for a $144^{\circ}$ angle) found in a substituted tetrahedryltetrahedrane ${ }^{17}$. 
Table 1. $\mathrm{C}_{2} \mathrm{H}_{6}$ : C-C bond dissociation energies (De), equilibrium distances $(\AA)$ of $C C(R(C C))$ and $C H(R(C H)$, hydrogen distance $(\mathrm{d}(\mathrm{H} \ldots \mathrm{H}))$ of closer vicinal hydrogens as a function of $\mathrm{CCH}$ angles (see Fig.1); CCSD(T)/CCpVQZ level.

\begin{tabular}{llcllll}
\hline$<\mathrm{CCH}$ & $120^{\circ}$ & opt $\left(111.2^{\circ}\right)$ & $100^{\circ}$ & $90^{\circ}$ & $80^{\circ}$ & $70^{\circ}$ \\
\hline $\mathrm{R}(\mathrm{CC})$ & 1.483 & 1.527 & 1.628 & 1.830 & 2.231 & 2.9 \\
$\mathrm{R}(\mathrm{CH})$ & 1.097 & 1.091 & 1.085 & 1.079 & 1.079 & 1.089 \\
$\mathrm{~d}(\mathrm{H} \ldots \mathrm{H})$ & 2.75 & 2.59 & 2.27 & 2.12 & 2.14 & 2.38 \\
$\mathrm{De}{ }^{(\mathrm{a})}$ & 132.6 & 111.4 & 81.6 & 44.5 & 15.4 & 5.6 \\
$\mathrm{De}^{(\mathrm{b})}$ & 84.8 & 96.6 & 79.2 & 44.5 & 13.0 & -9.2
\end{tabular}

aith respect to $2 \mathrm{CH}_{3}$ of the same geometry; ${ }^{b}$ with respect to planar $\mathrm{CH}_{3}$.

Two sets of dissociation energies are given in Table 1, according to the reference fragments $\mathrm{CH}_{3}$ : dissociation energy with respect to two $\mathrm{CH}_{3}$ fragments in the same geometry as in $\mathrm{C}_{2} \mathrm{H}_{6}$ is assumed to be closer to an in-situ bond energy, whereas dissociation energy with respect to $\mathrm{CH}_{3}$ in their optimal planar geometry refers to potential experimentally determined thermodynamic bond dissociation energy.

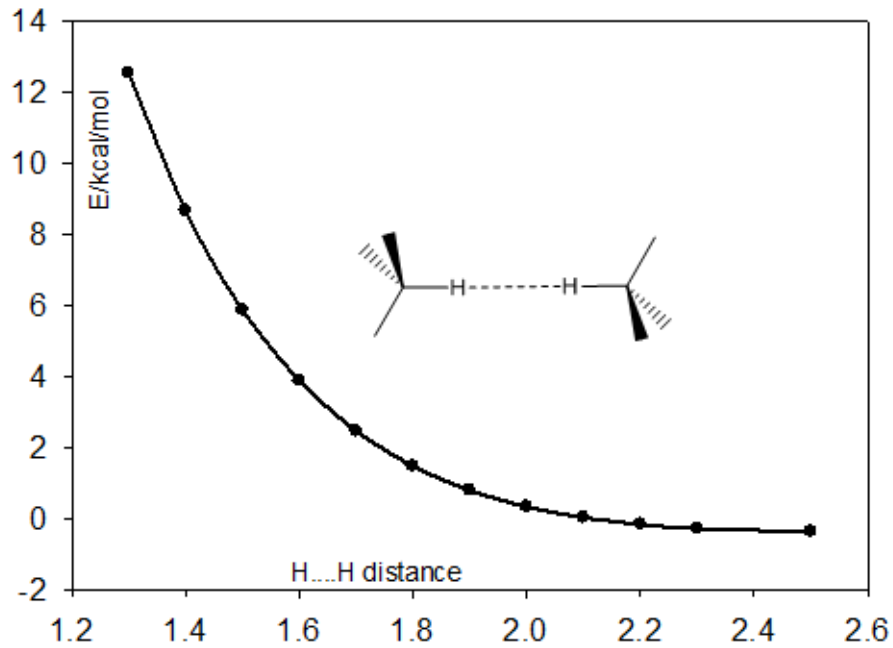

Figure 2. Interaction energy $(\mathrm{kcal} / \mathrm{mol})$ in $\mathrm{H}_{3} \mathrm{C}-\mathrm{H} \ldots \mathrm{H}-\mathrm{CH}_{3}$ as a function of $\mathrm{H}$...H distance $(\AA)$.

In order to verify that the optimized $\mathrm{C}-\mathrm{C}$ distances were not controlled by $\mathrm{H}$...H repulsions, the repulsion energy for a couple $\mathrm{H}$.... $\mathrm{H}$ was evaluated by calculating the energy of $\mathrm{H}_{3} \mathrm{C}-\mathrm{H}$... $\mathrm{H}-\mathrm{CH}_{3}$ at various $\mathrm{H}$...H distances (Fig. 2). In all cases, the $\mathrm{H}$...H distances in optimized $\mathrm{C}_{2} \mathrm{H}_{6}$ are greater than 2.1 $\AA$. For this value, the repulsion energy of a couple $\mathrm{H} . . . \mathrm{H}$ is ca. $0.02 \mathrm{kcal} / \mathrm{mol}$. Considering that six such interactions appear in $\mathrm{C}_{2} \mathrm{H}_{6}$, the total repulsion is less than $2 \mathrm{kcal} / \mathrm{mol}$ and should have a very weak effect on the $\mathrm{C}$-C optimization and thus on the calculated bond energy.

The $\mathrm{H} . . . \mathrm{H}$ repulsion can be even turned out in models of "semi-inverted" bonds, where only one $\mathrm{CH}_{3}$ group interacts in an inverted geometry, yielding to negligible or missing vicinal hydrogen interactions. As a first example, semi-inverted ethane (scheme 1) has an in-situ De of $27.2 \mathrm{kcal} / \mathrm{mol}$ (CCSD(T)/cc-pVQz), which drops to $-20.6 \mathrm{kcal} / \mathrm{mol}$ if measured with respect to planar $\mathrm{CH}_{3}$ groups. 


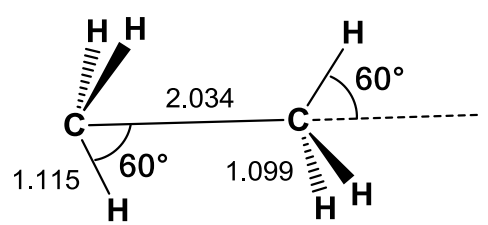

Scheme 1. "Semi-inverted" C-C bond. Distances in Å.

A second example is the semi-inverted $\mathrm{CH}_{3}-\mathrm{C} \equiv \mathrm{CH}$ systems, whose the variation of $D e$ as a function of the HCC angle is displayed in Fig. 3 (MP2/cc-pVTZ). Due to hyperconjugation, the $\mathrm{CH}_{3}-\mathrm{C}$ bond is stronger than in the corresponding $\mathrm{CH}_{3}-\mathrm{CH}_{3}$ systems (the experimental value in propyne is 126.5 $\mathrm{kcal} / \mathrm{mol} \mathrm{vs.} 90.1 \mathrm{kcal} / \mathrm{mol}$ for ethane ${ }^{18}$ ), but drops to ca. $64 . \mathrm{kcal} / \mathrm{mol}$ for $\mathrm{HCC}=60^{\circ}$.

Both examples show that the bond energy decreases dramatically even with the inversion of just one $\mathrm{CH}_{3}$ group.

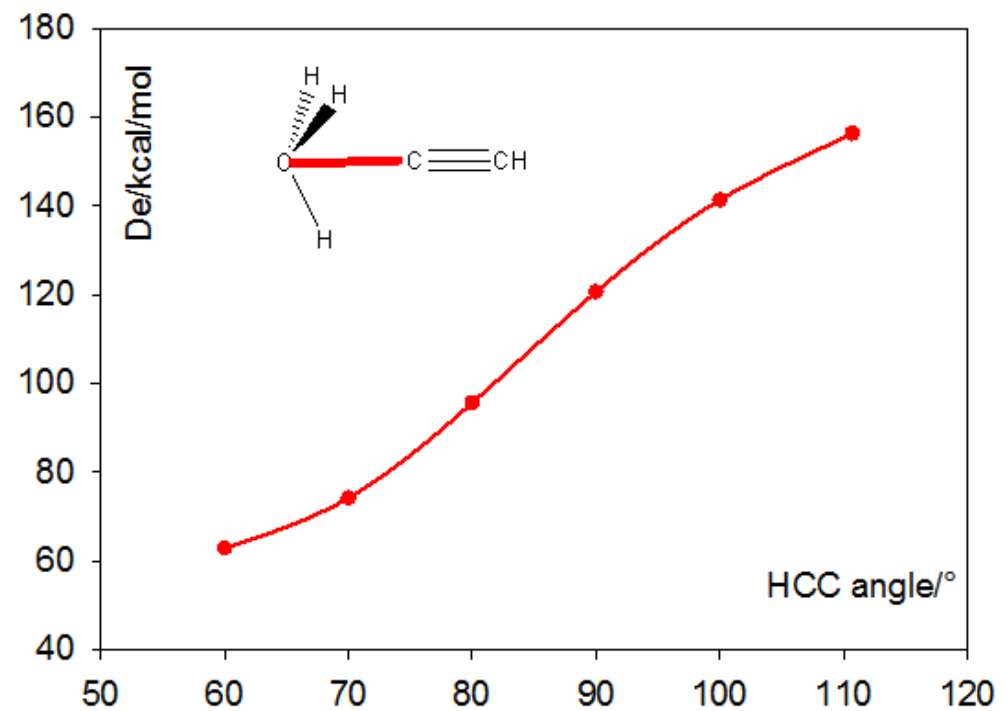

Figure. 3. Semi inverted C-C dissociation energy De in constrained propyne systems (with respect to fragments with the same geometry).

\section{Bonding analysis by Dynamic Orbital Forces (DOF) and evaluation of in-situ bond energies}

\subsection{MO analysis of [1.1.1] propellane 1 and [1.1.1] bicyclopentane 2}

The valence shell MOs of 1 are displayed in Fig. 4. The MOs are labelled in order of decreasing energy from 1 (HOMO) to 13. We report the Dynamic Orbital Force (DOF) for each C-C bond. 


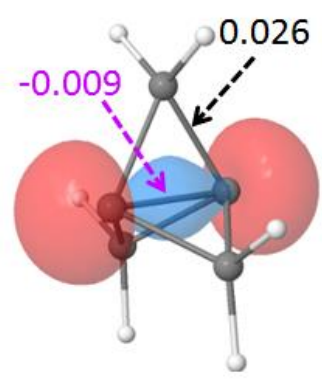

1. $\operatorname{HOMO}\left(a^{\prime}{ }_{1}\right)$

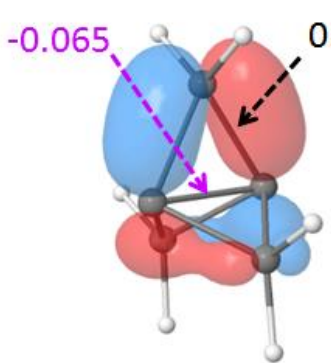

$2-3\left(e^{\prime \prime}\right)$
0.169

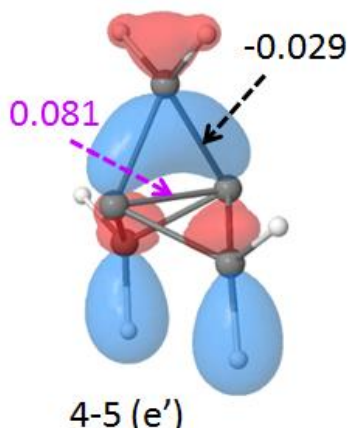

4-5 (e')

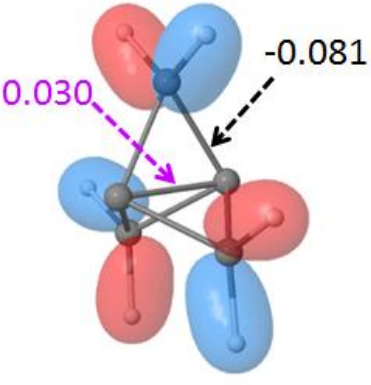

$6\left(a_{2}^{\prime}\right)$

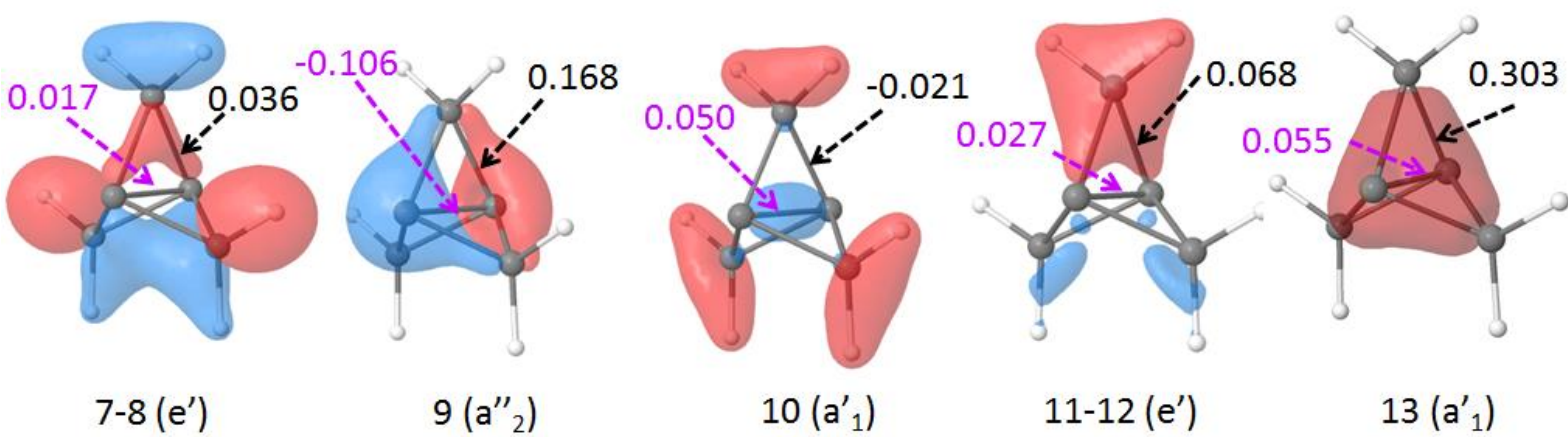

Figure. 4. Valence shell MOs of propellane. DOF (au) of central (purple; left value) and wing (black; right value) $\mathrm{CC}$ bond. Only one MO of each degenerate set is reported

The HOMO a' ${ }_{1}$ associated to the "inverted bond" of propellane is slightly antibonding (negative DOF) along the central CC bond, as previously pointed out on the same grounds. ${ }^{7}$ This result is somewhat counterintuitive because in this $\mathrm{MO}$ there is no nodal plane cutting the bond; it comes from the fact that most of the electron density is located in the repulsive part of the space, as defined by Berlin, ${ }^{19}$ essentially out of the internuclear area. Note that similar MOs are found in more familiar systems, such as the highest $\sigma_{\mathrm{g}}{ }^{+} \mathrm{MO}$ of $\mathrm{N}_{2}(\mathrm{DOF}=0.047), \mathrm{P}_{2}(\mathrm{DOF}=-0.008), \mathrm{S}_{2}(\mathrm{DOF}=-0.019)$ and $\mathrm{As}_{2}(\mathrm{DOF}=$ 0.003). These MOs are weakly or very weakly bonding or even antibonding. The $\sigma_{\mathrm{g}}{ }^{+} \mathrm{LUMO}$ of $\mathrm{C}_{2}$, in its dominant configuration, also belongs to the same "inverted" type, with a DOF of -0.003 . Other propellane MOs contribute to a $\sigma$-type bonding between the central carbon atoms, in the sense that they are partly located on the C-C C $C_{3}$ symmetry axis: the $a^{\prime}{ }_{1}$ MOs 10 and 13 are bonding and the a" ${ }_{2}$ MO 9 is strongly antibonding. A previous ELF analysis points in the same direction, showing that the main contributions $(75 \%)$ to this $\sigma$ bond arise from other MOs than the HOMO. ${ }^{20}$ The MOs of e' or $\mathrm{e}^{\prime \prime}$ symmetry, possessing a nodal surface containing the central bond can be referred to as $\pi$-type MOs (or bridge MOs or "banana" MOs). The a' ${ }_{2} \mathrm{MO} 6$, located on $\mathrm{CH}_{2}$ groups, does not belong to the preceding types, but has nevertheless a noticeable bonding character along the central CC bond. Taking into account that e' and e" MOs correspond to two electron pairs, it appears, at first glance, that the central $\mathrm{C}-\mathrm{C}$ bonding is ensured essentially by $\pi$-type interactions. 

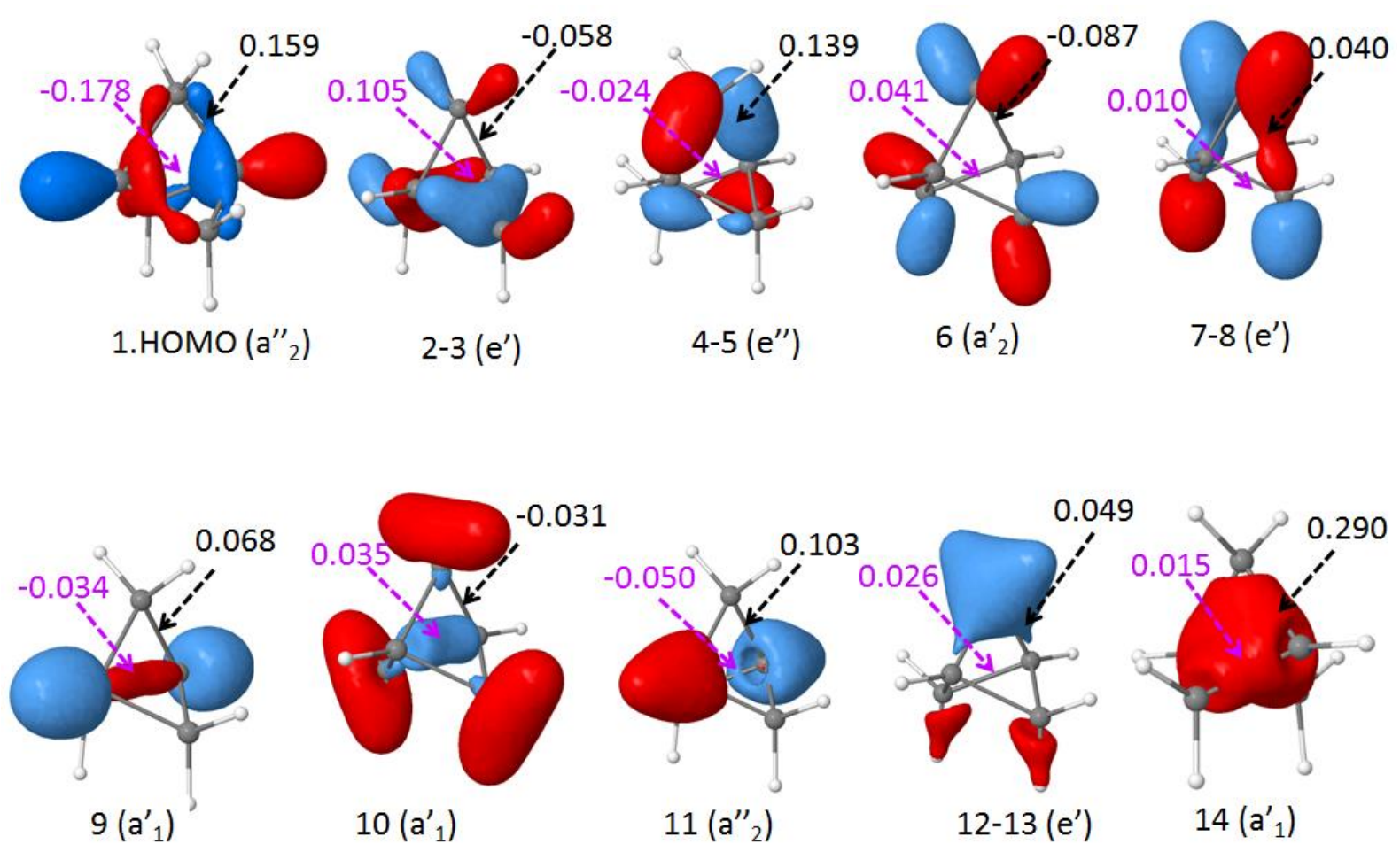

Figure 5. Valence shell MOs of bicyclopentane 2. DOFs (a.u.) of the central (purple; left value) and wing (black; right value) $\mathrm{CC}$ bonds. Only one $\mathrm{MO}$ of each degenerate set has been reported

In order to further delve on the nature of these orbitals, we have also analyzed [1.1.1]bicyclopentane 2. The MOs of $\mathbf{2}$ mainly differ from the preceding ones by the HOMO $\mathrm{a}^{\prime \prime}{ }_{2}$, which is strongly antibonding, resulting from the 4-electron interaction of the $\sigma$ orbitals of both $\mathrm{C}-\mathrm{H}$ bonds at a very short CC distance (ca. $1.88 \AA$ A). Carbon-hydrogen bonding in the two $\mathrm{C}-\mathrm{H}$ groups is essentially ensured by the HOMO (DOF $=0.064)$ and the MOs $9(\mathrm{DOF}=0.186)$ and $11(\mathrm{DOF}=0.109)$.

\subsection{Evaluation of in-situ bond energies}

Although the sum $\Sigma$ of DOFs over occupied MOs is not equal to the total force exerted by electrons on nuclei, this quantity has been recognized as a comparative index of the strength of similar bonds. ${ }^{21}$ Indeed, considering the $\mathrm{C}_{2} \mathrm{H}_{6}$ inverted series, the calculated bond dissociation energies are correlated to $\Sigma$. These quantities are reported in Table 2 , in which we also report $\Sigma_{\sigma}$, the DOF sum of $\sigma$ MOs, (MOs of $\mathrm{a}_{1 \mathrm{~g}}$ and $\mathrm{a}_{2 \mathrm{u}}$ symmetry). As expected, $\Sigma$ is close to $\Sigma_{\sigma}$, which means that $\pi$ interactions play a minor role in the bonding. 
Table 2. DOF (a.u), $\Sigma$, sum of DOFs and $\Sigma_{\sigma}$, sum of DOFs of $\sigma$-type MOs (of $a_{1 g}$ and $a_{2 u}$ symmetry) over occupied MOs for $\mathrm{C}_{2} \mathrm{H}_{6}$ with various $\mathrm{HCH}$ angles (cf. Fig. 1).

\begin{tabular}{|c|c|c|c|c|c|c|c|c|c|c|}
\hline \multicolumn{2}{|c|}{$120^{\circ}$} & $111.2^{\text {o(a) }}$ & \multicolumn{2}{|c|}{$100^{\circ}$} & \multicolumn{2}{|c|}{$90^{\circ}$} & \multicolumn{2}{|c|}{$80^{\circ}$} & \multicolumn{2}{|c|}{$70^{\circ}$} \\
\hline $\mathrm{MO}$ & DOF & DOF & $\mathrm{MO}$ & DOF & $\mathrm{MO}$ & DOF & MO & DOF & $\mathrm{MO}$ & DOF \\
\hline $\mathrm{e}_{\mathrm{g}} \mathrm{HO}$ & -0.056 & -0.056 & $\mathrm{a}_{1 \mathrm{~g}} \mathrm{HO}$ & 0.126 & $a_{1 g}$ & 0.091 & $a_{1 g}$ & 0.043 & $a_{1 g}$ & 0.025 \\
\hline$a_{1 g}$ & 0.126 & 0.118 & $e_{g}$ & -0.060 & $e_{g}$ & -0.042 & $e_{g}$ & -0.034 & $e_{g}$ & -0.017 \\
\hline$e_{u}$ & 0.060 & 0.061 & $e_{u}$ & 0.061 & $e_{u}$ & 0.037 & $e_{u}$ & 0.034 & $e_{u}$ & 0.013 \\
\hline$a_{2 u}$ & -0.041 & -0.050 & $a_{2 u}$ & -0.054 & $a_{2 u}$ & -0.049 & $a_{2 u}$ & -0.049 & $a_{2 u}$ & -0.022 \\
\hline$a_{1 g}$ & 0.126 & 0.128 & $a_{1 g}$ & 0.104 & $a_{1 g}$ & 0.082 & $a_{1 g}$ & 0.063 & $a_{1 g}$ & 0.022 \\
\hline$\Sigma_{\sigma}$ & 0.410 & 0.392 & & 0.352 & & 0.248 & & 0.114 & & 0.050 \\
\hline$\Sigma$ & 0.436 & 0.412 & & 0.356 & & 0.228 & & 0.114 & & 0.034 \\
\hline
\end{tabular}

(a) optimized value

The correlation curves of $\Sigma$ with "in situ" and "thermodynamic" bond energies as defined in the first section (from Table 1 and Table 2 ) are reported in Fig. 6 . As expected, the two curves are close to one another as far as the energy of planar and pyramidal $\mathrm{CH}_{3}$ are almost of the same energy, and diverge when the two values differ, i.e. for higher and lower HCC values.

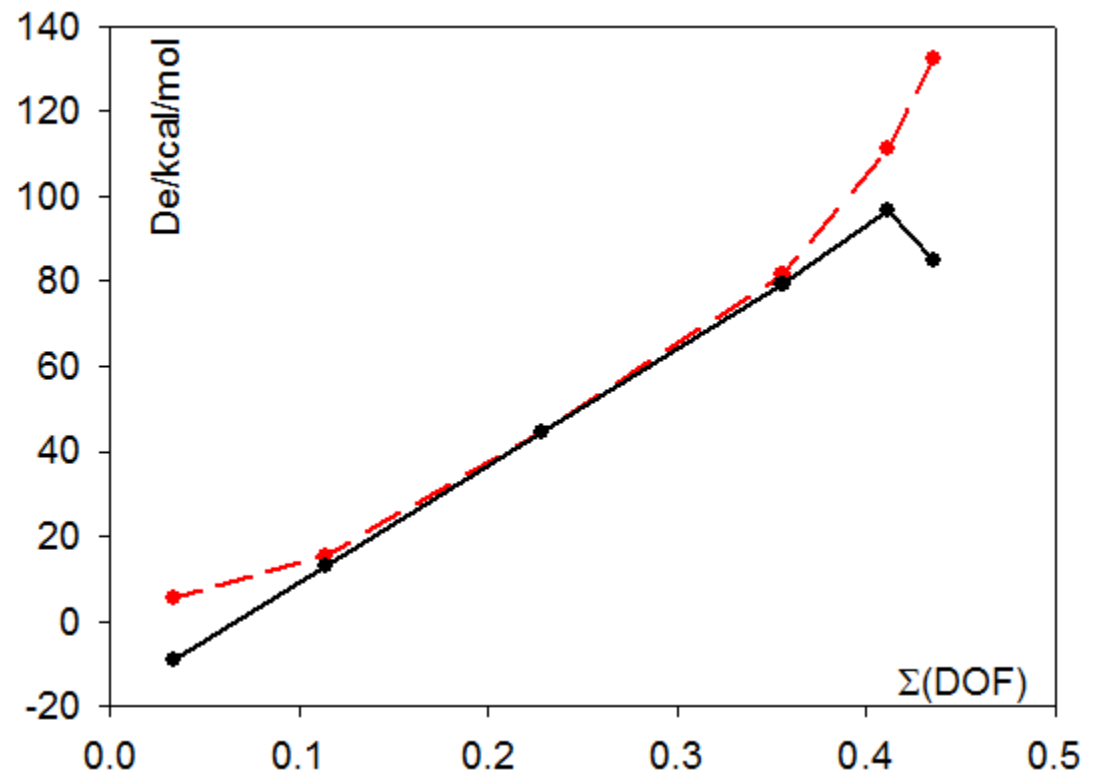

Figure 6. In-situ bond energy (red dashed curve) and bond dissociation energy (black curve) of $\mathrm{C}_{2} \mathrm{H}_{6}$ as a function of $\Sigma$ (DOF) (a.u.) from Table 2.

The results of Fig. 6 can be used to evaluate, by interpolation on the red curve, the in-situ energy of a bond of a given $\Sigma$ (DOF) in the range $\Sigma=0-0.45$. We will see that this process is reasonable though it involves several assumptions. Firstly, we used an interpolation method, because the exact function $D e=f(\Sigma)$ is unknown. Secondly, the DOFs may present some marginal error due to the impossibility to increment only one bond length in cyclic structures, keeping constant all the other geometrical internal parameters. In this case, we chose to keep all other bond lengths constant, which requires variations in the angles, however smaller than one degree in all cases. In order to discard this source 
of error, we found that a similar angular deviation in propane has a negligible effect $\left(<10^{-3} \mathrm{au}\right)$ on its DOFs. Last, the $\mathrm{CH}_{3}$ fragments used in the calculations have the same geometrical structure, but not the same electronic structure as in $\mathrm{C}_{2} \mathrm{H}_{6}$ and thus do not fulfill exactly the conditions of in-situ bond energy. However, taking into account that the $\mathrm{C}-\mathrm{C}$ bond is not polar, the electron transfer in the bond formation should be weak. Taking all these sources of error into consideration, we can estimate a total uncertainty is smaller than $10 \%$. As a reference, the experimental bond dissociation energy of ethane $(90.1 \mathrm{kcal} / \mathrm{mol})^{18}$ is close to its calculated intrinsic bond energy $(86.6 \mathrm{kcal} / \mathrm{mol})^{22}$.

Results for propellane 1, its corresponding ${ }^{2} A^{\prime}{ }_{1}$ cation and its $A^{\prime \prime}{ }_{2}$ triplet state are given in Table 3 . We report the DOFs of frontier MOs, their sum $\Sigma$ for each bond (CC refers to the central bond and WCC to the other "wing" CC bonds) and the corresponding bond energies. For the central bond, we also report $\Sigma_{\pi}$ corresponding to $\pi$-type MOs (of e' and e" symmetry) and $\Sigma_{\sigma}$ corresponding to $\sigma$-type MOs (of a symmetry). Nevertheless, in the latter case, the $\mathrm{a}_{2}^{\prime} \mathrm{MO}$ ( $\mathrm{n}^{\circ} 6$ in Fig. 4) can be hardly identified as a $\sigma \mathrm{MO}$ and its DOF has been included in $\Sigma_{\pi}$.

Table 3. Propellane in ground, cationic $\left({ }^{2} A^{\prime}{ }_{1}\right)$ and triplet $\left({ }^{3} A^{\prime \prime}{ }_{2}\right)$ states. DOF (a.u.) of frontier MOs; sums of DOFs (a.u.) over occupied MOs $\left(\Sigma_{\sigma}\right.$ : $\sigma$-contributing; $\Sigma_{\pi}$ : $\pi$-contributing; $\Sigma$ : total); De: in-situ bond energies $(\mathrm{kcal} / \mathrm{mol})$; $\mathrm{R}(\mathrm{CX})$ bond lengths ( $\AA$, MP2/cc-pVTZ). CC refers to the central bond, WCC to the wing $\mathrm{CH}_{2}-\mathrm{C}$ bonds.

\begin{tabular}{|c|c|c|c|c|c|c|c|}
\hline \multicolumn{4}{|c|}{ Propellane (1) } & \multicolumn{2}{|c|}{$(1)^{+}\left({ }^{2} A^{\prime}{ }_{1}\right)$} & \multicolumn{2}{|c|}{ triplet $(\mathbf{1})\left({ }^{3} A^{\prime \prime}{ }_{2}\right)$} \\
\hline MO & $\operatorname{DOF}(\mathrm{CC})$ & DOF(WCC) & $\mathrm{DOF}\left(\mathrm{CH}_{2}\right)$ & $\mathrm{MO}$ & $\mathrm{DOF}(\mathrm{CC})$ & MO & DOF(CC) \\
\hline$a_{2} " L U M O$ & -0.111 & -0.022 & -0.008 & LUMO & -0.098 & SOMO & -0.095 \\
\hline$a_{1}{ }^{\prime}$ HOMO & -0.009 & 0.026 & -0.011 & SOMO & -0.005 & SOMO & -0.028 \\
\hline$\Sigma_{\sigma}$ & -0.018 & & & & 0.038 & & -0.110 \\
\hline$\Sigma_{\pi}$ & 0.295 & & & & 0.343 & & 0.410 \\
\hline$\Sigma$ & 0.286 & 1.744 & 1.931 & & 0.381 & & 0.300 \\
\hline$\Sigma /$ bond & 0.286 & 0.291 & 0.322 & & 0.381 & & 0.300 \\
\hline $\mathrm{De}$ & 61.3 & 62.8 & & & 88.8 & & 65.4 \\
\hline$R(C X)$ & 1.5956 & 1.5173 & 1.0821 & & 1.5400 & & 1.8064 \\
\hline
\end{tabular}

The negative value $(-0.018)$ of $\Sigma_{\sigma}$ at the central CC bond indicates that the $\sigma$ interaction is globally slightly repulsive: the so-called "inverted bond", as arising from a $\sigma$ overlap of $s-p$ hybrids by their smaller lobes, should actually have a slightly negative energy. The bond is thus totally ensured by $\pi$ type (banana) MOs, as already concluded by Allen et al. ${ }^{3}$ and its energy can be estimated to ca. 60 $\mathrm{kcal} / \mathrm{mol}$. For the wing CC bonds, the $\sigma-\pi$ distinction is no longer relevant, because some MOs may appear at the same time of $\sigma$ type on some bonds and of $\pi$ type on other ones. They present a $\Sigma$ value per bond $(0.291 \mathrm{au})$ slightly greater than that of the central bond $(0.286 \mathrm{au})$ and are thus expected to show a slightly greater energy $(\approx 3 \mathrm{kcal} / \mathrm{mol})$. All the CC bond energies of propellane $(\approx$ $60-63 \mathrm{kcal} / \mathrm{mol}$ ) are less than those of cyclopropane, whose intrinsic bond energy has been evaluated to $73.2 \mathrm{kcal} / \mathrm{mol}^{22}$

Further insight into the nature of the central $\mathrm{C}-\mathrm{C}$ bond can be obtained from the analysis of cationic propellane ${ }^{2} \mathrm{~A}^{\prime}{ }_{1}$. In this species, one electron is removed from the weakly antibonding HOMO of propellane and the bond length is moderately reduced, down to that of a standard C-C bond (1.54 
$\AA$ A).The sum $\Sigma_{\sigma}$ becomes slightly positive; moreover, the $\pi$-type interactions increase with respect to the neutral species. As a result, an overall bond energy of ca. $89 \mathrm{kcal} / \mathrm{mol}$ is found, close to that of ethane (exp. dissociation energy: $90.1 \mathrm{kcal} / \mathrm{mol}^{18}$; intrinsic bond energy $86.6 \mathrm{kcal} / \mathrm{mol}^{22}$ ).

The repulsive $\sigma$ interactions in propellane can be fostered by electron excitation. In triplet ${ }^{3} \mathrm{~A}_{2}{ }_{2}$ state, one electron occupies the $a^{\prime \prime}{ }_{2}$ SOMO which is rather antibonding. With respect to ground state species, we observe a stronger repulsive $\sigma$ interaction compensated by an increased bonding $\pi$ interaction leading to a total bond energy of ca. $65 \mathrm{kcal} / \mathrm{mol}$.

Results for bicyclopentane neutral, cationic and di-cationic are given in Table 4. Alike in the propellane case, the $a_{2}^{\prime} \mathrm{MO}\left(n^{\circ} 6\right.$ in Fig. 5) has been considered as participating to a $\pi$-type interaction. Note that the cationic species have been frozen in $D_{3 \mathrm{~h}}$ symmetry and are not zeroth order stationary points: they are reported as probes of the bonding properties in bicyclopentane.

Table 4. Bicyclopentane in ground $\left({ }^{1} A^{\prime}{ }_{1}\right)$, cationic $\left({ }^{2} A^{\prime \prime}{ }_{2}\right)$ and dicationic $\left({ }^{1} A^{\prime}{ }_{1}\right)$ states. DOF (a.u.) of highest occupied MOs; sums of DOFs over occupied MOs ( $\Sigma_{\sigma}: \sigma$-contributing; $\Sigma_{\pi}: \pi$-contributing; $\Sigma$ : total); De: in-situ bond energies (kcal/mol); $R(C X)$ bond lengths ( $\AA$, MP2/cc-pVTZ). CC refers to the central bond, WCC to the wing $\mathrm{CH}_{2}-\mathrm{C}$ bonds.

\begin{tabular}{|c|c|c|c|c|c|c|c|c|}
\hline & \multicolumn{4}{|c|}{ Bicyclopentane $(2)\left({ }^{1} A^{\prime}{ }_{1}\right)$} & \multicolumn{2}{|c|}{$(2)^{+}\left({ }^{2} A^{\prime \prime}{ }_{2}\right)$} & \multicolumn{2}{|c|}{$(2)^{2+}\left({ }^{1} A^{\prime}{ }_{1}\right)$} \\
\hline & $\mathrm{DOF}(\mathrm{CC})$ & DOF(WCC) & $\mathrm{DOF}(\mathrm{CH})$ & $\operatorname{DOF}\left(\mathrm{CH}_{2}\right)$ & MO & $\mathrm{DOF}(\mathrm{CC})$ & MO & $\mathrm{DOF}(\mathrm{CC})$ \\
\hline $\mathrm{a}_{2}$ "HOMO & -0.178 & 0.159 & 0.064 & -0.034 & $\mathrm{a}_{2}$ "SOMO & -0.120 & e"HOMO & -0.074 \\
\hline$\Sigma \sigma$ & -0.430 & & 0.502 & 1.519 & & 0.045 & & 0.252 \\
\hline$\Sigma \pi$ & 0.556 & & & & & 0.472 & & 0.284 \\
\hline$\Sigma$ & 0.126 & 1.680 & 0.502 & 1.519 & & 0.517 & & 0.536 \\
\hline$\Sigma /$ bond & 0.126 & 0.280 & 0.251 & 0.253 & & 0.517 & & 0.536 \\
\hline De & 18.5 & 59.7 & & & & 129.2 & & 137.0 \\
\hline$R(C X)$ & 1.8758 & 1.5503 & 1.0874 & 1.0895 & & 1.6456 & & 1.4576 \\
\hline
\end{tabular}

In bicyclopentane $2, \Sigma_{\sigma}$ is strongly negative along the central CC couple, mainly due to the strongly antibonding character of the HOMO. This repulsive interaction is compensated by a strong bonding $\pi$-type interaction, resulting in a weakly positive bond energy of ca. $20 \mathrm{kcal} / \mathrm{mol}$. Though these small differences must be considered with caution, the other "wing" C-C bonds look slightly stronger in 1 that in $\mathbf{2}$ by about $3 \mathrm{kcal} / \mathrm{mol}$.

The strong antibonding character of the a" ${ }_{2} \mathrm{HOMO}$ of $\mathbf{2}$ along CC agrees with the evolution of this bond energy when two electrons are subsequently removed from this $\mathrm{MO}$. These bond energies are out of the range of Figure 6 and have been evaluated by interpolation from the calculated intrinsic bond energies $^{22}$ of benzene ( $\left.D e=120.5 \mathrm{kcal} / \mathrm{mol} ; \Sigma=0.496\right)$ and ethylene $(D e=139.1 \mathrm{kcal} / \mathrm{mol} ; \Sigma=$ 0.552). 
The examination of the cationic species highlights the strongly antibonding character of the HOMO of 2. In the monocation, the $\sigma$-type interaction becomes slightly positive and the $\mathrm{CC}$ bond energy increases dramatically up to ca. $130 \mathrm{kcal}$. This trend increases in the dication, with a bond energy of ca. $140 \mathrm{kcal} / \mathrm{mol}$, similar to that of ethylene, with a bond length of $1.46 \AA$.

\section{Conclusion}

The $\mathrm{C}_{2} \mathrm{H}_{6}$ models of 'inverted' $\mathrm{C}-\mathrm{C}$ bonds suggest that the bond energy decreases rapidly with the inversion angle and tends to zero, if not negative values, with the same angular constraints as in propellane. This trend is comforted by models of 'semi-inverted' bonds $\mathrm{C}_{2} \mathrm{H}_{6}$ and $\mathrm{CH}_{3}-\mathrm{C} \equiv \mathrm{CH}$. Moreover, $\mathrm{MO}$ analysis using dynamic orbital forces (DOF) shows that the $\sigma$-type interactions in the central CC bond of propellane are slightly repulsive. This bonding is thus only due to $\pi$-type (or 'banana') bonds. The correlation between the bond energy and the sum of DOFs over occupied MOs allows to expect an in-situ bond energy of ca. $60 \mathrm{kcal} / \mathrm{mol}$ for this bond. On the same grounds, a weak bond $(15-20 \mathrm{kcal} / \mathrm{mol})$ should exist between the corresponding carbon atoms of bicyclopentane 2 despite a strong $\sigma$-type repulsion and the absence of a formal bond.

Keywords: [1.1.1.]propellane , Inverted bond, Molecular Orbitals, Orbital Force, Bond energy.

\footnotetext{
${ }^{1}$ K. B. Wiberg, F. H. Walker, J. Am. Ckem. Soc. 1982, 104, 5239-5240

${ }^{2}$ D. Feller, E. R. Davidson, J. Am. Chem. Soc. 1987, 109, 4133-4139

${ }^{3}$ J. E. Jackson, L. C. Allen, J. Am. Chem. Soc 1984, 106, 591-599

${ }^{4}$ T. Kar, K. Jug, Chem. Phys. Lett. 1996, 256, 201-206

${ }^{5}$ W. Wu, J. Gu, J. Song, S. Shaik, P. C. Hiberty Angew. Chem. 2009, 121, $1435-1438$

${ }^{6}$ M. D. Newton, J. M. Schulman, J. Am. Chem. Soc. 1972, 94, 773.

${ }^{7}$ W. Stohrer, R. Hoffmann, J. Am. Chem. Soc. 1972, 94, 779.

${ }^{8}$ E. Honegger, H. Huber, E. Heilbronner, J. Am. Chem. Soc. 1985, 107, 7172-7174

${ }^{9}$ O. Schafer, M. Allan, G. Szeimies, M. Sanktjohansert, J. Am. Chem. Soc. 1992,114,8180-8186

${ }^{10}$ M. Messerschmidt, S. Scheins, L. Grubert, M.I Pätzel, G. Szeimies, C. Paulmann, P. Luger, Angew. Chem. Int. Ed. 2005, 44, $3925-3928$.

${ }^{11}$ F.W. Averill, G. S Painter, Phys. Rev. B 1986, 34(4) 2088-2095.

12 a) R.F. W. Bader, A.D. Bandrauk, J. Chem. Phys. 1968, 49, 1653-1665.; b) R. F. W Bader, J. Keaveny, P. E. Cade,. J. Chem. Phys., 1967, 47, 3381-3402. ; c) P. E. Cade, R.F.W. Bader, W.H. Henneker, I. Keaveny,. J. Chem. Phys. 1969, 50, 5313-5333.

${ }^{13}$ a) T. Tal, J. Katriel, Theoret. Chim. Acta 1977, 46 173-181; b) F.M.Bickelhaupt, J. K. Nagle, W.L. Klemm, J. Phys. Chem. A 2008, 112, 2437-2446; c) P.J. Robinson, A.N. Alexandrova, J. Phys. Chem. A 2015, 119, 12862-12867

${ }^{14}$ a) P. Chaquin, Y. Canac , C. Lepetit, D. Zargarian, R. Chauvin, Int. J. Quant. Chem. 2016, 116, 1285-1295; b) P. Chaquin, F. Fuster, F. Volatron, Int. J. Quant. Chem 2018, 118, 25658-25659

${ }^{15}$ P. Chaquin, F. Fuster, ChemPhysChem. 2017, 18, 2873- 2880

${ }^{16}$ Gaussian 09, Revision A.01, M. J. Frisch, G. W. Trucks, H. B. Schlegel, G. E. Scuseria, M. A. Robb, J. R. Cheeseman, G. Scalmani, V. Barone, B. Mennucci, G. A. Petersson, H. Nakatsuji, M. Caricato, X. Li, H. P. Hratchian, A. F. Izmaylov, J. Bloino, G. Zheng, J. L. Sonnenberg, M. Hada, M. Ehara, K. Toyota, R. Fukuda, J. Hasegawa, M. Ishida, T. Nakajima, Y. Honda, O. Kitao, H. Nakai, T. Vreven, J. A. Montgomery, Jr., J. E. Peralta, F. Ogliaro, M. Bearpark, J. J. Heyd, E. Brothers, K. N. Kudin, V. N. Staroverov, R. Kobayashi, J. Normand, K. Raghavachari, A. Rendell, J. C. Burant, S. S. Iyengar, J. Tomasi, M. Cossi, N. Rega, J. M. Millam, M. Klene, J. E. Knox, J. B. Cross, V. Bakken, C. Adamo, J. Jaramillo, R. Gomperts, R. E. Stratmann, O. Yazyev, A. J. Austin, R.
} 
Cammi, C. Pomelli, J. W. Ochterski, R. L. Martin, K. Morokuma, V. G. Zakrzewski, G. A. Voth, P. Salvador, J. J. Dannenberg, S. Dapprich, A. D. Daniels, Ö. Farkas, J. B. Foresman, J. V. Ortiz, J. Cioslowski, D. J. Fox, Gaussian, Inc., Wallingford CT, 2009.

${ }^{17}$ M. Tanaka, A. Sekiguchi, Angew. Chem. Int. Ed. 2005, 44, 5821-5823

${ }^{18}$ S. J. Blanksby, G. B. Ellison, Acc. Chem. Res., 2003, 36 (4), 255-263

${ }^{19}$ T. J. Berlin, Chem. Phys. 1951, 19(2), 208-213.

${ }^{20}$ V. Polo, J. Andres, B. Silvi, J. Comput. Chem. 2007,28, 857-864.

${ }^{21}$ a) Y. Yamaguchi, R.B. Remington, J.F. Gaw, H. F. Schaefer III, G. Frenking, Chem. Phys. 1994, 180, 55-70; b) Y. Yamaguchi, R.B. Remington, J.F. Gaw, H. F. Schaefer III, G. Frenking, J. Chem. Phys. 1993, 98 (11), 8749-8760; c) Yamaguchi, B. J. DeLeeuw, C. A. Richards, Jr., H. F. Schaefer III, G. Frenking, J. Am. Chem. Soc. 1994, 116, 11922-11930

${ }^{22}$ K. Exner, P. von Ragué Schleyer, J. Phys. Chem. A 2001, 105, 3407-3416. 